\title{
A 42-year-old male presenting as pericardial mass
}

\author{
Hyun Ju Yoon ${ }^{1}\left[\right.$ Kye Hun Kim ${ }^{1} \cdot$ Jae Yeong Cho ${ }^{1} \cdot$ Hyuk Jin Park ${ }^{1} \cdot$ Hyung Yoon Kim ${ }^{1} \cdot$ Jong Chun Park $^{1}$
}

Received: 21 August 2018 / Revised: 4 September 2018 / Accepted: 5 September 2018 / Published online: 1 October 2018

(c) The Author(s) 2018

A 42-year-old man visited to emergency room due to abdominal pain that had started $8 \mathrm{~h}$ before. He has no underlying medical illness except a history of repair of ventricular septal defect at 20 years ago. He had a history of patch closure due to ventricular septal defect 20 years ago and was a 20 -packyear ex-smoker.

In physical examination, there was abdominal tenderness around umbilicus, his blood pressure was $150 / 100 \mathrm{mmHg}$. For the purpose of evaluation of abdominal pain, abdominal computed tomography (CT) was checked. His CT showed a $4.5 \times 4 \times 5$-cm-sized well-defined unilocular cystic mass in the right lower anterior mediastinum. The mass had internal calcification, hemorrhage and an enhancing solid portion, suggesting mature cystic teratoma or cystic thymoma. It showed a slight mass effect on the right atrium (Fig. 1b, c, d). In echocardiography, abnormal shunt flow was not found, septal bouncing motion and mixed echogenic pericardial mass compressing the right atrium were detected (Fig. 1d). For tissue diagnosis, the mass was resected and the right atrial wall was repaired.

Pathology confirmed that this $6.7 \times 5.5 \times 4.0-\mathrm{cm}$-sized mass was a retained gauze at the time of surgery 20 years ago (Fig. 1e, f). The patient had a dramatic improvement and discharged.

"Gossypiboma" is a technical term for surgical complications resulting from foreign materials. It originated from the Latin word for cotton, "gossypium" plus "boma" which means a place of concealment in Swahili. The term is related to the fact that surgical gauze was made with cotton in the past. It is now made from other materials, so the term does not really fit the current situation [1]. It has been reported that it has an incidence of 1 in every 5500-18,760 operations, happening more commonly in abdominal cavity surgery. Because it is usually asymptomatic and can often be associated with lawsuits, the incidence tends to be under reported [2].

There have been several studies to unearth the potential risk factors associated with retained surgical items. The most commonly found retained foreign body was the surgical sponge. Multivariate analysis showed that emergency operation, unexpected change in surgical procedure, and high BMI of the patient were risk factors for retention of a foreign body [3].

To minimize the events, scrupulous surgical counting should be held as dictated by the governing hospital protocol and a new count should be performed whenever there is change in the surgical team or the intended procedure. Using small-sized pads and sponges should be avoided if possible as they can easily lodge between the tissues and bowel loops and stain with blood, making their identification difficult [4].

Hyun Ju Yoon

ann426@hanmail.net

1 Cardiology Department, Chonnam National University

Hospital, 42 Jaebong-ro, Donggu, Gwangju 501-757,

South Korea 


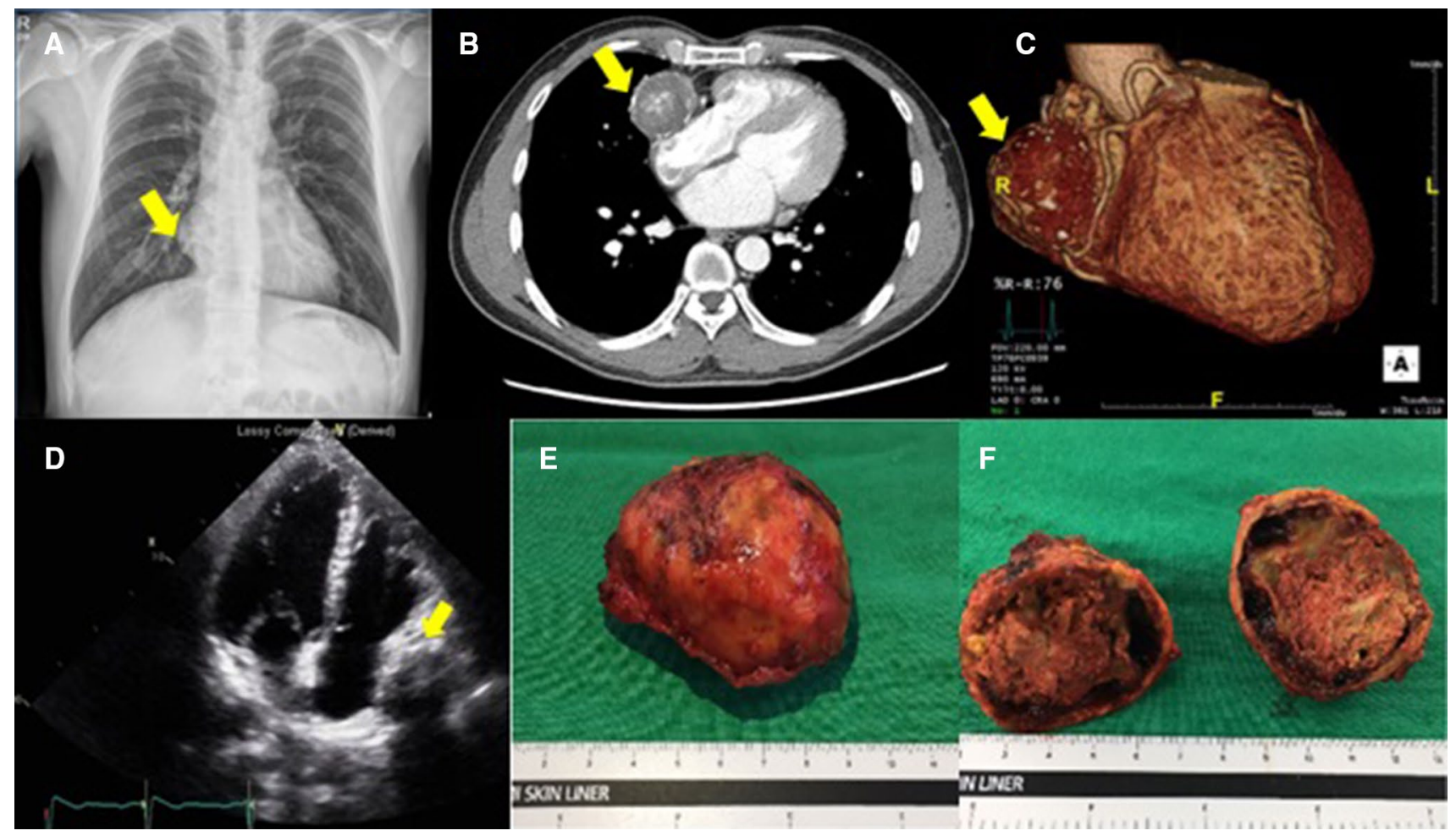

Fig. 1 a Chest PA showed bulging contour of right heart border, b, c. Chest CT showed pericardial mass in anterior mediastinum, d. Echocardiography showed pericardial mass beside right atrium, e, f. Isolated pericardial mass was dissected

\section{Compliance with ethical standards}

Conflict of interest Hyun Ju Yoon, Kye Hun Kim, Jae Yeong Cho, Hyuk Jin Park, Hyung Yoon Kim and Jong Chun Park declare that they have no conflict of interest.

Human rights statements All procedures followed were in accordance with the ethical standards of the responsible committee on human experimentation (institutional and national) and with the Helsinki Declaration of 1964 and later revisions.

Informed consent Informed consent was obtained from all patients for being included in the study.

Open Access This article is distributed under the terms of the Creative Commons Attribution 4.0 International License (http:// creativecommons.org/licenses/by/4.0/), which permits unrestricted use, distribution, and reproduction in any medium, provided you give appropriate credit to the original author(s) and the source, provide a link to the Creative Commons license, and indicate if changes were made.

\section{References}

1. Gencosmanoglu R, Inceoglu R. An unusual cause of small bowel obstruction: gossypiboma-case report. BMC Surg. 2003;3:6.

2. Gawande AA, Studdert DM, Orav EJ, et al. Risk factors for retained instruments and sponges after surgery. N Engl J Med. 2003;348:229-35.

3. Stawicki SP, Moffatt-Bruce SD, Ahmed HM, et al. Retained surgical items: a problem yet to be solved. J Am Coll Surg. 2013;216:15-22.

4. Lincourt AE, Harrell A, Cristiano J, et al. Retained foreign bodies after surgery. J Surg Res. 2007;138:170-4. 